The potential of Streptococcus salivarius oral films in the management of dental caries: an inkjet printing approach

Cornelius C. Dodoo ${ }^{1,2}$, Paul Stapleton ${ }^{1}$, Abdul Basit ${ }^{1}$, Simon Gaisford $^{1 *}$

${ }^{1}$ School of Pharmacy, University College London, 29-39 Brunswick Square, London, WC1N $1 \mathrm{AX}, \mathrm{UK}$

${ }^{2}$ Present Address: School of Pharmacy, University of Health and Allied Sciences, PMB 31, Ho, Ghana

*Corresponding author: Simon Gaisford (s.gaisford@ucl.ac.uk)

\title{
ORCID details
}

Cornelius C. Dodoo (0000-0003-4369-8245)

Paul Stapleton

Abdul Basit (0000-0002-5368-6603)

Simon Gaisford (0000-0003-1000-3208)

\section{Graphical abstract}

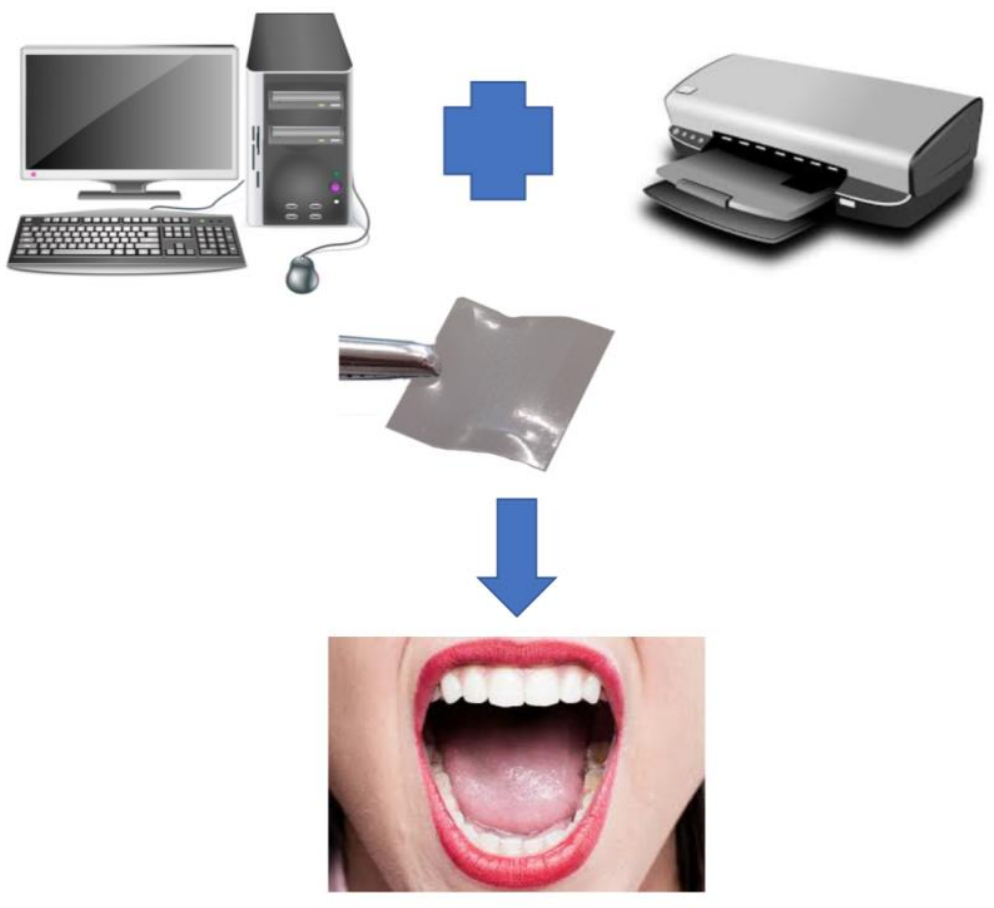




\begin{abstract}
Oral infections like dental caries are major public health issues globally. Management of these conditions include methods like brushing, tongue cleaning and dental flossing with or without the use of antibiotics. A major challenge with these management approaches is the difficulty to obtain complete eradication of the disease-causing organisms. An alternative approach is the use of probiotics, which can be administered in oro-dispersible films (ODFs), and which have prolonged activity in the mouth. ODFs made of xylitol and containing Streptococcus salivarius were formulated using inkjet printing and tested against Streptococcus mutans - a causative organism of dental caries. The testing of the prepared ODFs involved co-incubating ink-jetted formulation of S. salivarius and xylitol with $S$. mutans and monitoring the microbial growth kinetics in real-time using isothermal microcalorimetry and colony plate counts. Cell-free supernatants (CFS) of S. salivarius were also tested against $S$. mutans. Prior to the formulation the phosphate solubilisation potential of S. salivarius was determined and found to be negative, a sign that the species will not deplete phosphate from teeth. From the tests, it was observed that the formulation reduced $S$. mutans population from 7.9 to 5.04-Log CFU/mL post-calorimetry (approximately 3-Log reduction) which was comparable to the $99.9 \%$ reduction expected during antimicrobial activity testing. A gradual decrease in $S$. mutans population was also observed with increasing of $S$. salivarius CFS volumes indicative of pathogen suppression. This study demonstrates that $S$. salivarius can be useful in managing dental caries and ODFs of $S$. salivarius can be formulated easily using ink-jetting for such management.
\end{abstract}

Keywords: oro-dispersible films, inkjet printing, probiotics, dental caries, isothermal microcalorimetry 


\section{Introduction}

Infections and diseases of the oral cavity usually occur due to changes in the resident oral microbiota. A balance between the beneficial and pathogenic bacteria determines the oral health of an individual. Dental caries and periodontal diseases are globally considered the two most important oral health problems (Caglar et al., 2005, Bizzini et al., 2012, Ladewig et al., 2018, Lin et al., 2017). The impact of these on individuals is significant; the pain and impairment of function accompanying dental caries and periodontal disease is considerable (Bizzini et al., 2012, Hujoel et al., 2018, Gaurilcikaite et al., 2017).

Methods of treatment include mechanical removal via brushing, tongue cleaning and dental flossing of the bacteria/plaque with or without antibiotics (Yao and Fine, 2014, Dommisch et al., 2018). However, it is difficult to achieve complete eradication with most of these organisms repopulating quickly and recolonising the oral surfaces once antimicrobial use is stopped. These agents also stay in the mouth at effective doses only for a short period (minutes) and are mainly below minimum inhibitory levels for prolonged periods (hours) (Cagetti et al., 2013, Marsh, 2003, Burton et al., 2005, Heinemann et al., 2013).

An ecological approach to treatment has been proposed involving the administration of nonvirulent bacteria (i.e. probiotics) to prevent recolonisation of these pathogenic species after antimicrobial therapy. These can also be adopted for use after rinsing with oral antiseptics, such as chlorhexidine. Treating oral infections by reducing the pathogenic bacterial population and facilitating a favourable environment that allows teeth remineralisation has been suggested to halt disease progression (Bizzini et al., 2012, Dhawan and Dhawan, 2013, Wescombe et al., 2012, Tagg and Dierksen, 2003). Some commercial products that have probiotics incorporated for promoting oral health include ProBiora $3{ }^{\circledR}$, PerioBalance ${ }^{\circledR}$, KForce Breath Guard ${ }^{\circledR}$ mouthwash and lozenges, and various probiotic forms of BLIS K12 (Yao and Fine, 2014, Bizzini et al., 2012, Tagg and Dierksen, 2003).

Consumer interest in the possible preventative and health maintenance benefits of oral probiotics, as well as research into oral health claims have led to an increased interest in the use of probiotics in oral health (Bowen, 2012, Marsh, 2003, Chugh et al., 2020, Tester and Al-Ghazzewi, 2018). A few organisms have been used experimentally in oral probiotics 
evaluations. Chewing gums made with strains of Lactobacillus reuteri ATCC 55730/ATCC PTA 5289 have been shown to reduce levels of Streptococcus mutans significantly (Caglar et al., 2009). Lactobacillus rhamnosus GG and Streptococcus salivarius K12 are also commonly used in oral probiotic formulations (Meurman, 2005, Caglar et al., 2005). An ideal approach in the treatment of oral diseases would be the ability to deliver or apply a formulation directly into the mouth that stays in there for an extended period. Oro-dispersible films (ODFs) are a delivery mechanism that can be used to achieve this. ODFs involve a costeffective manufacturing process and are easy to use as a dosage form. It is an innovative way of personalising medicines extemporaneously for both local and systemic delivery (Krampe et al., 2016, Preis et al., 2013, Buanz et al., 2015, Heinemann et al., 2013). Solvent casting and hot melt extrusion (HME) are formulation approaches generally adopted; both require the drug to be mixed into the polymer matrix. The very high temperature that accompanies HME and the use of organic solvents in solvent casting are major drawbacks with these techniques (Scarpa et al., 2017, Maniruzzaman et al., 2012, Krampe et al., 2016).

The possibility of formulating probiotic oral films using inkjet printing for the treatment of oral infections was therefore explored. Probiotic ODFs were formulated using S. salivarius and xylitol combination to help in the management of dental caries caused by S. mutans. We have previously used the inkjet printer to personalise warfarin doses as well as print combination formulations of triiodothyronine and thyroxine for hypothyroidism (Vuddanda et al., 2018, Alomari et al., 2018).

Ink-jetting is a non-contact technique that offers advantages like high throughput and high reproducibility (Wilson and Boland, 2003, Lemmo et al., 1998, Alper, 2004). A modified Hewlett-Packard printer (HP 5940 Deskjet) was used in this work for formulation (Dodoo et al., 2019a, Alomari et al., 2018).

\section{Materials and Methods}

\subsection{Growth media and reagents used}

Columbia blood agar, MRS (de Man, Rogosa, and Sharpe) agar, nutrient agar, cooked meat medium, anaerobe basal broth, defibrinated horse blood, and mitis salivarius agar were 
obtained from Oxoid, UK. Phosphate-buffered saline tablets, 1/4 Ringer's solution tablets, and glycerol were purchased from Fisher Scientific, UK. Trehalose, xylitol, and glucose were from Sigma-Aldrich, UK. Bacitracin was from the Wellcome Trust, UK.

\subsection{Organisms}

The microorganisms used were Streptococcus salivarius NCTC 8618 and Streptococcus mutans NCTC 10449. These were obtained as a gift from UCL Eastman Dental Institute, London.

\subsection{Culture stock preparation}

Culture stock preparation and storage was done using a method as described by Said et al., (2014). S. salivarius and S. mutans were grown on Columbia blood agar supplemented with $5 \%$ defibrinated horse blood $\left(\mathrm{CBA}_{\mathrm{hb}}\right)$ and incubated under anaerobic conditions for 48 hours at $37^{\circ} \mathrm{C}$. A colony was taken and used to inoculate $7 \mathrm{~mL}$ of anaerobe basal broth supplemented with 5\% horse blood to create a starter culture and incubated for 24 hours. 99 $\mathrm{mL}$ of fresh anaerobe basal broth supplemented with 5\% horse blood was inoculated with 1 $\mathrm{mL}$ of the starter culture to create a 1:100 dilution and this was incubated for 24 hours. The culture was then mixed using a magnetic stirrer to ensure homogeneity and dispensed into falcon tubes. Centrifugation and washing of the cells were then done as reported previously. The cells were resuspended in $1 / 4$ Ringer's solution supplemented with $15 \%$ v $/ v$ glycerol. 1.8 $\mathrm{mL}$ of the culture was rapidly dispensed aseptically into $2 \mathrm{~mL}$ cryovials (Nunc). Sealed vials were immersed gently into liquid nitrogen for 10 minutes after which the frozen vials were stored in a freezer at $-80^{\circ} \mathrm{C}$. Post-freezing enumeration was $10^{6} \mathrm{CFU} / \mathrm{mL}$ for both species.

\subsection{Determination of optimum concentration of xylitol against $S$. mutans}

A stock solution $(10 \% \mathrm{w} / \mathrm{v})$ of xylitol in water was prepared. Different volumes were added to cooked meat medium supplemented with $2 \% \mathrm{w} / \mathrm{v}$ glucose $(\mathrm{CMMg})$ to give final xylitol concentrations of $(0.1,0.5,1,5 \% \mathrm{w} / \mathrm{v})$ in sterile $3 \mathrm{~mL}$ calorimetric glass ampoules. Thawed cultures of $S$. salivarius and $S$. mutans were then inoculated separately at $30 \mu \mathrm{L}$ of $10^{6}$ 
$\mathrm{CFU} / \mathrm{mL}$ into the ampoules. The ampoules were sealed with crimped caps and vortexed for 10 seconds. Calorimetric readings were taken afterwards.

Based on the results, $0.5 \%$ xylitol solution was chosen as the optimum xylitol concentration that inhibited $S$. mutans but was tolerated by $S$. salivarius. $0.5 \%$ xylitol was also chosen since higher xylitol concentrations like $1 \%$ affected the cartridge performance and ability of the cartridges to be reused due to nozzle clogging. The amount of xylitol that had to be ink-jetted onto acetate paper to give a concentration equivalent to $0.5 \%$ xylitol solution in a $3 \mathrm{ml}$ ampoule was determined. A calibration curve for xylitol between $0.5 \mathrm{mg} / \mathrm{mL}$ and $30 \mathrm{mg} / \mathrm{mL}$ was obtained using HPLC. A stock solution of xylitol $(0.5 \mathrm{~g} / \mathrm{mL})$ was prepared and used to deposit templates of varying dimensions onto acetate paper. The print-outs were then carefully cut and immersed in $1 \mathrm{~mL}$ deionised water to dissolve the xylitol. The xylitol solution was vortexed to ensure complete dissolution after which HPLC analysis for xylitol as described in the United States Pharmacopoeia (2012) was conducted.

The liquid chromatographic system used was Agilent Technologies 1200 series with a quaternary pump and degasser. The column used was a Phenomenex SCX column (250 mm x $4.60 \mathrm{~mm}, 5 \mu \mathrm{m})$. The mobile phase consisted of water: acetonitrile mixture (80:20) with a flow rate of $0.5 \mathrm{ml} / \mathrm{min}$. A column temperature of $80{ }^{\circ} \mathrm{C}$ and wavelength of $192 \mathrm{~nm}$ were used for detection. Each assay was run for 10 mins.

\subsection{Phosphate ion solubilisation assay}

Phosphate ion solubilisation was assessed using in-house prepared Pikovskaya agar plates. The composition of the prepared Pikovskaya agar is indicated in Table 1. A $10 \mu \mathrm{L}$ aliquot of exponentially grown culture was spot-inoculated on plates and incubated at $37^{\circ} \mathrm{C}$ for 14 days. S. salivarius was tested and $S$. mutans used as a positive control. 
Table 1: Pikovskaya medium composition in $1 \mathrm{~L}$

\begin{tabular}{|l|l|}
\hline Ingredient & Quantity (g) \\
\hline Glucose & 10 \\
\hline Tricalcium Phosphate & 5 \\
\hline Ammonium sulphate & 0.5 \\
\hline Yeast extract & 0.5 \\
\hline Sodium chloride & 0.2 \\
\hline Potassium chloride & 0.2 \\
\hline Magnesium sulphate heptahydrate & 0.1 \\
\hline Manganese sulphate monohydrate & 0.002 \\
\hline Ferrous sulphate heptahydrate & 0.002 \\
\hline Agar & 20 \\
\hline
\end{tabular}

\subsection{Evaluating antibacterial properties of $S$. salivarius and xylitol formulation}

The antibacterial property of the probiotic formulation was investigated against $S$. mutans using calorimetry with CMMg used as the growth medium. Frozen S. salivarius cells were thawed in a water bath at $40{ }^{\circ} \mathrm{C}$ for 3 minutes. 3 vials (each with a population of $10^{6}$ $\mathrm{CFU} / \mathrm{mL}$ ) were concentrated together to give $10^{7} \mathrm{CFU} / \mathrm{mL}$. A power-time curve of $S$. mutans $\left(10^{4} \mathrm{CFU} / \mathrm{mL}\right)$ co-incubated with ink-jetted S. salivarius $(2 \mathrm{~cm} \mathrm{x} 15 \mathrm{~cm})$ and xylitol $(2 \mathrm{~cm} \mathrm{x}$ $16 \mathrm{~cm}$ ) formulation was obtained. Post-calorimetry plating was conducted after $24 \mathrm{~h}$ using mitis salivarius agar and mitis salivarius agar supplemented with $15 \%$ sucrose and 0.2 i.u of bacitracin per $\mathrm{mL}$ to differentiate between the two streptococci. As a reference, pure cultures of both species were streaked onto plates containing both media.

A cell-free supernatant (CFS) of $S$. salivarius was obtained and used in the antibacterial evaluation. CFS was obtained by incubating ink-jetted S. salivarius in CMMg for 5 days. This was then centrifuged at $9500 \mathrm{rpm}$ and $4{ }^{\circ} \mathrm{C}$ for 10 mins. The supernatant was then decanted and filtered using $0.22 \mu \mathrm{m}$ diameter filters to obtain the CFS. Varying volumes of the CFS were added to ampoules containing CMMg inoculated with S. mutans and the calorimeter used to monitor growth. 


\section{Results}

\subsection{Determination of optimum concentration of xylitol against $S$. mutans}

Data from isothermal calorimetry are usually represented as a plot of power against time. The power signal, in this instance, arises due to metabolic heat in which is directly proportional to the bacterial population in the system (Braissant et al., 2010). The area under the curve (AUC) hence represents heat energy (Joules) and gives an indication of the number of organisms in the system (Braissant et al., 2013, Kabanova et al., 2009).

The effect of varying xylitol concentration on growth and metabolism of $S$. salivarius and $S$. mutans are shown in Figure 1.
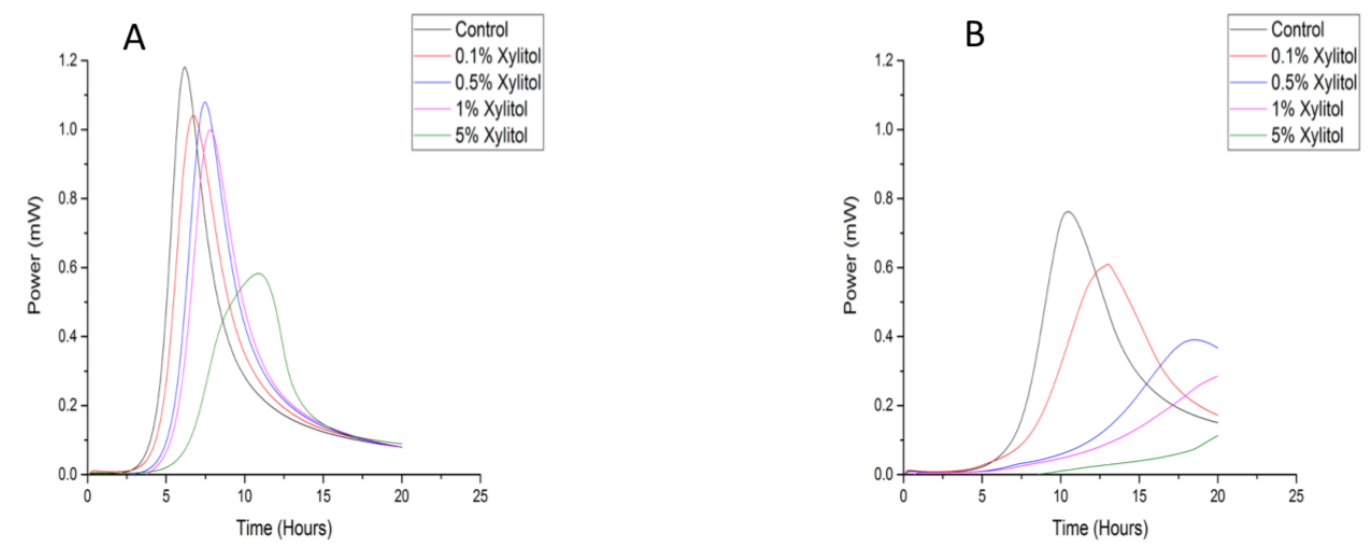

Figure 1: Effect of varying xylitol concentrations on S. salivarius growth (A) and S. mutans growth (B)

The AUCs which give an indication of the cumulative heat output are represented in Figure 2. It was observed that increasing xylitol concentrations to $1 \%$ did not have any significant impact on S. salivarius metabolism. Peaks of similar characteristics were obtained for the concentrations used except 5\% xylitol. A different scenario was observed for S. mutans, xylitol concentration as low $0.1 \%$ was enough to result in delayed metabolism, a concentration of $0.5 \%$ resulted in a very delayed onset of metabolism. 


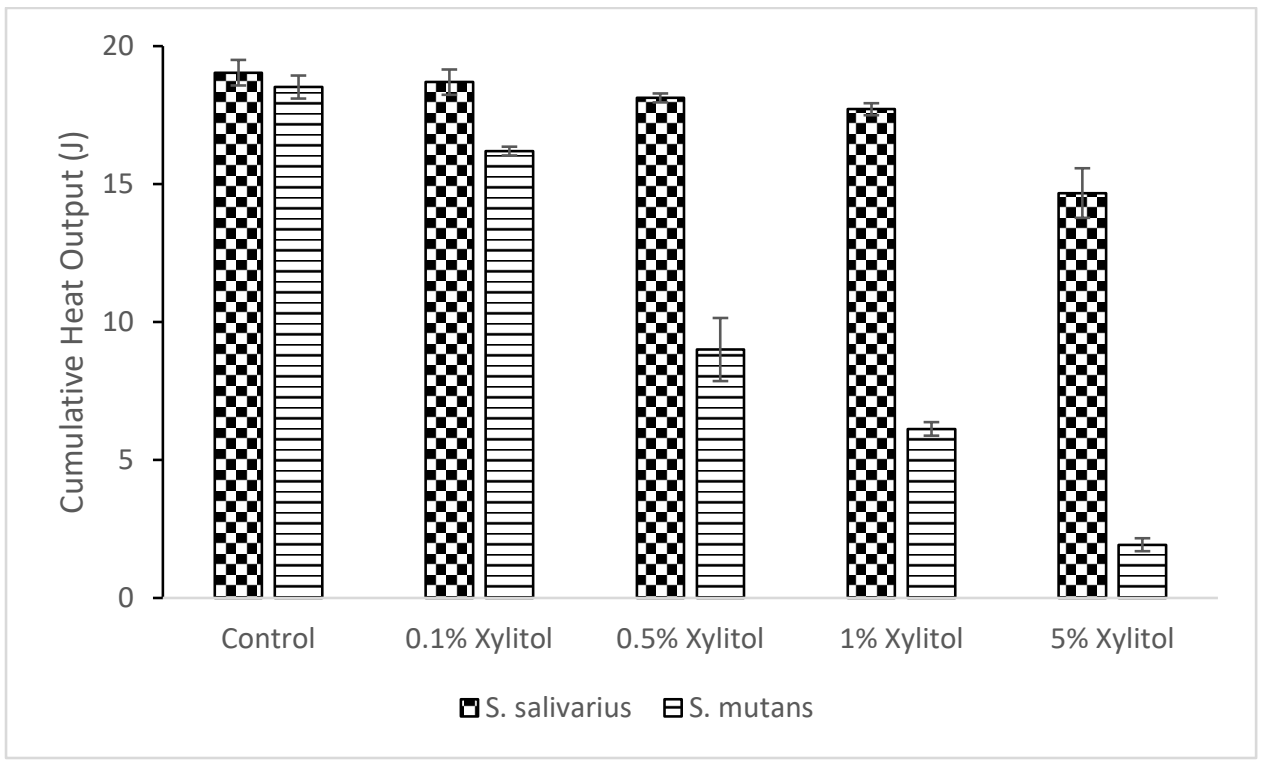

Figure 2: Cumulative heat output after $24 \mathrm{~h}$ representative of total AUC for S. salivarius and S. mutans under varying xylitol concentrations.

A calibration curve was obtained for xylitol in the range 0.5 to $32 \mathrm{mg} / \mathrm{ml}$ using HPLC, Figure 3. Varying template dimensions as indicated in Table 2 were used to deposit the xylitol concentrations. These dimensions were chosen since the amount of liquid deposited with these dimensions maintained the integrity of the substrate with no breaks the substrate. After obtaining the AUCs as indicated in Table 2, the AUC that was similar to that of $15 \mathrm{mg} / \mathrm{mL}$ as computed in Equation 1 was determined. It was observed that $2 \mathrm{~cm} \times 16 \mathrm{~cm}$ was the dimension with AUC (2830.20 \pm 16.46$)$ closest to 2369.70 representing $15 \mathrm{mg} / \mathrm{ml}$. Hence, this dimension was used to deposit xylitol solution for co-incubation with $S$. mutans in the calorimeter. 


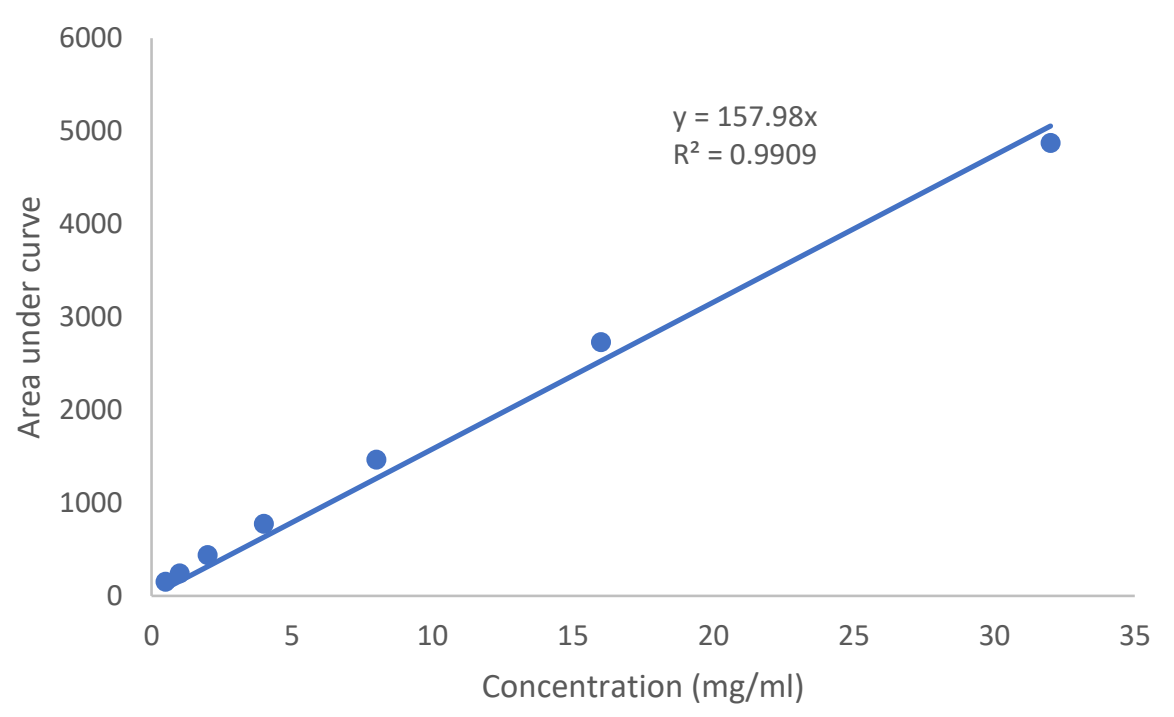

Figure 3: Calibration curve for xylitol in the range 0.5 to $32 \mathrm{mg} / \mathrm{ml}$

Table 2: Varying template dimensions used for ink-jetting xylitol and corresponding AUC $(n=3)$

\begin{tabular}{|l|l|}
\hline Template Dimension $(\mathrm{cm} \times \mathbf{~ c m})$ & AUC \\
\hline $1 \times 1$ & $149.10 \pm 19.98$ \\
\hline $1 \times 2$ & $277.00 \pm 29.09$ \\
\hline $1 \times 4$ & $434.87 \pm 20.46$ \\
\hline $1 \times 8$ & $802.13 \pm 2.42$ \\
\hline $1 \times 16$ & $1540.40 \pm 14.68$ \\
\hline $\mathbf{2} \times 1$ & $275.20 \pm 7.88$ \\
\hline $\mathbf{2} \times \mathbf{2}$ & $495.00 \pm 12.13$ \\
\hline $\mathbf{2} \times \mathbf{4}$ & $820.83 \pm 17.29$ \\
\hline $\mathbf{2} \times \mathbf{8}$ & $1574.60 \pm 41.58$ \\
\hline $\mathbf{2} \times 16$ & $2830.20 \pm 16.46$ \\
\hline
\end{tabular}

Equation 1: Expected AUC using calibration curve equation

$$
\begin{gathered}
y=157.98 x \\
\text { when } x=15 \\
y=2369.7
\end{gathered}
$$


A signal similar to $0.5 \%$ xylitol concentration was obtained when the ink-jetted xylitol was coincubated with $S$. mutans (Figure 4). The AUC obtained for $S$. mutans in the presence of the ink-jetted xylitol (11.48 \pm 0.78$)$ was higher than in the presence of $0.5 \%$ xylitol $(9.01 \pm 1.15)$. Considering that the ink-jetted xylitol had slightly more than $0.5 \%$ xylitol, it was expected to produce greater inhibition with a more delayed onset of $S$. mutans growth or slightly reduced peak intensity.

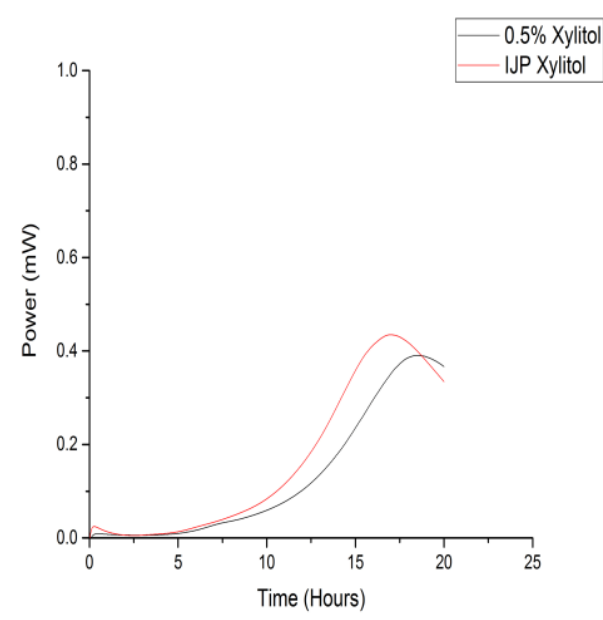

Figure 4: A Power-Time plot comparing metabolism of S. mutans in the presence of $0.5 \%$ xylitol and ink-jetted equivalent.

\subsection{Phosphate solubilisation assay}

After incubating organisms on Pikovskaya agar plates under anaerobic conditions for 14 days, a phosphate-solubilising organism presents a halo/clear zone with a diameter of at least $10 \mathrm{~mm}$ around the site of the inoculum (Goteti et al., 2014). This was observed for S. mutans with a halo of diameter $16 \mathrm{~mm}$ around the site of the inoculum whilst $S$. salivarius had a halo with diameter less than $2 \mathrm{~mm}$ (Figure 5). 

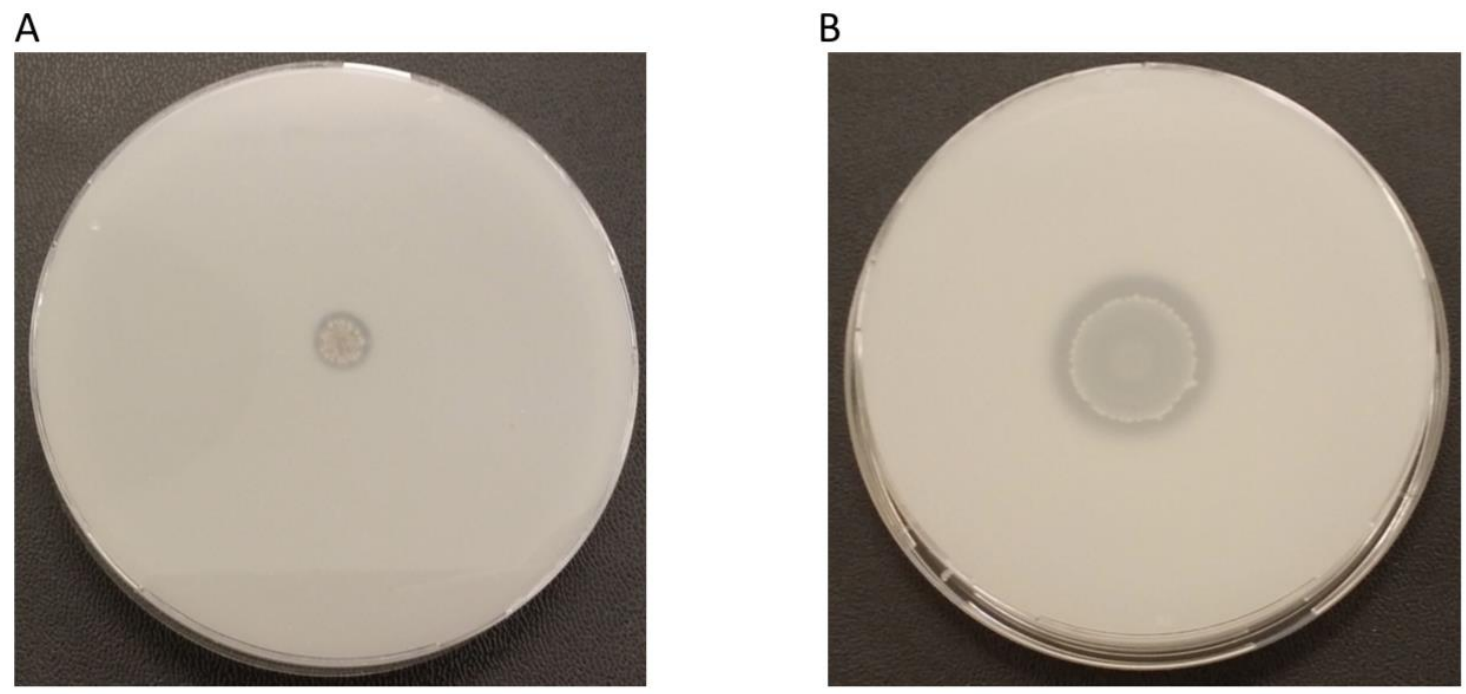

Figure 5: Images after incubating S. salivarius (A) and S. mutans (B) on pikovskaya agar with S. mutans having a halo with a diameter of $16 \mathrm{~mm}$ around the site of the inoculum

\subsection{Antibacterial properties of $S$. salivarius and xylitol formulation}

To evaluate the usefulness of the probiotic formulation - ODFs composed of ink-jetted $S$. salivarius and xylitol - in treating dental caries, it was co-incubated with $S$. mutans. The Power-Time plot (Figure 6A) showed that the signal obtained after co-incubating ODF had a relatively delayed onset and intensity in comparison to $S$. mutans and ink-jetted $S$. salivarius. Plate counting post-calorimetry (Figure 6B) revealed a drop in S. mutans population. 

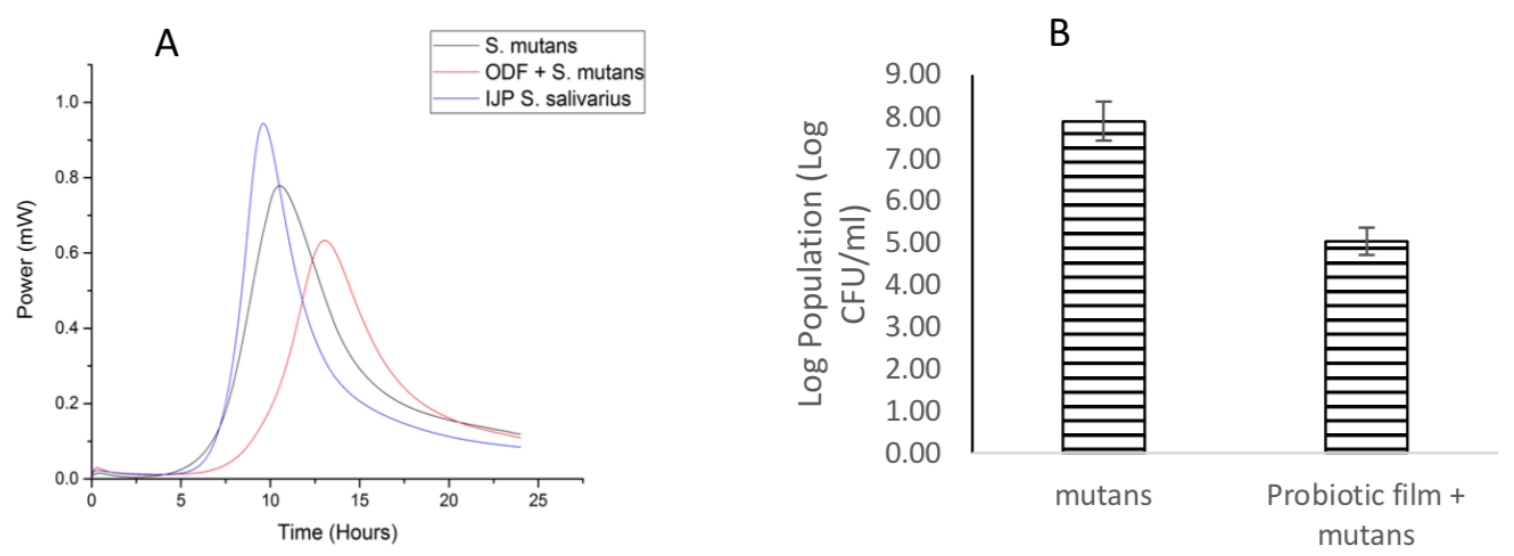

Figure 6: A) A Power-Time plot of S. mutans (control), ink-jetted (IJP) S. salivarius, and coincubation of probiotic oro-dispersible film (ODF) and S. mutans.

B) Colony plate counts of S. mutans control and S. mutans after co-incubating with probiotic ODF

To evaluate further antibacterial properties, varying amounts of cell-free supernatant (CFS) from $S$. salivarius were incubated with $S$. mutans. A Power-Time plot (Figure 7A) showed a reduction in peak intensity with increasing amounts of CFS. This highlighted a reduction in the metabolism of $S$. mutans in the presence CFS from $S$. salivarius. It must be noted that increasing the volume of CFS did not reduce the amount of growth medium available. The growth medium used here (cooked meat medium) unlike other media, does not dissolve when formulated. Hence, the same quantity of meat pellets was weighed into each ampoule for tests to ensure equal nutrient availability.

Plate counts when conducted at 11 hours, representative of highest signal intensity and metabolic activity is showed in Figure 7B. A gradual decrease in $S$. mutans population was observed with increasing CFS volume. 

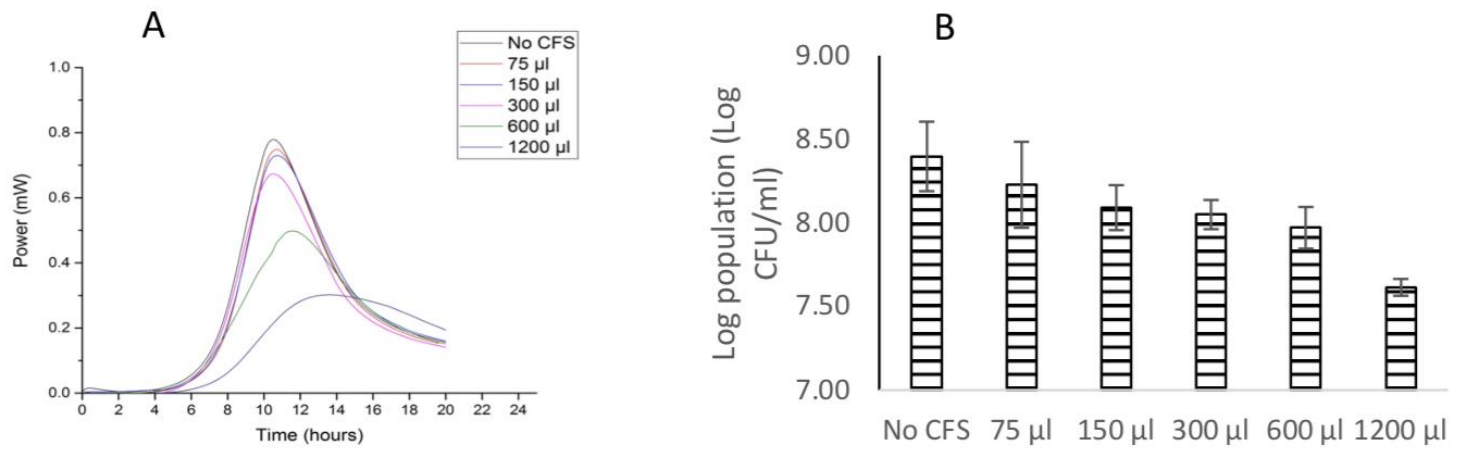

Figure 7: A) A Power-Time plot of S. mutans in varying amounts of S. salivarius cell-free supernatant B) Enumeration of S. mutans population at the highest signal intensity.

\section{Discussion}

Isothermal microcalorimetry was used to evaluate microbial growth kinetics. This provides real-time information and has been previously used in evaluating antibacterial activity of a number of agents (Dodoo et al., 2019b, Said et al., 2014, Fredua-Agyeman et al., 2017). Based on these results obtained in Figures 1 and 2, investigations were carried out to print an amount of xylitol onto a substrate that would present the same effect as $0.5 \%$ xylitol concentration in a $3 \mathrm{~mL}$ ampoule (i.e., $15 \mathrm{mg}$ xylitol in $3 \mathrm{~mL}$ ). A calibration curve (Figure 3) was obtained for xylitol in the range 0.5 to $32 \mathrm{mg} / \mathrm{ml}$ using HPLC. The calibration curve helped to extrapolate the amount of xylitol deposited for the varying dimensions of template printed. This was useful in obtaining a corresponding ink-jetted amount for $0.5 \%$ xylitol concentration as was observed in Figure 4.

Xylitol, unlike most sugars (sorbitol, fructose, glucose), is a 5-carbon sugar and inhibits glycolysis in S. mutans because it is a non-fermentable sugar (Ohshima et al., 2016, Cagetti et al., 2013, Marsh, 2003). Badet et al. (2008) reported on the importance of xylitol in preventing the formation of a multispecies biofilm and the relevance of using it for the prevention of oral diseases caused by dental plaque. Aside its antibacterial properties xylitol 
is also known to stimulate the secretion of saliva which helps in teeth mineralisation and remineralisation (Abou Neel et al., 2016, Hara and Zero, 2010).

Pikovskaya medium, a medium used in soil microbiology to evaluate phosphate solubilisation of by soil microorganisms was used to evaluate the phosphate solubilisation potential of the $S$. salivarius and S. mutans (Goteti et al., 2014, Kumar Meena et al., 2015). A very important, yet omitted, test in most oral probiotics' evaluation is the phosphate ion solubilising potential of probiotic organisms. Phosphate is an important ion needed for teeth mineralisation and remineralisation; it plays a significant role in the susceptibility of teeth to caries progression. The teeth are also comprised of a phosphate-based mineral, apatite, in the enamel and dentine (Abou Neel et al., 2016). Any activity that results in a decrease in phosphate amounts has implications on teeth integrity and should not be used for oral treatment or be used with caution. Streptococcus mutans, the primary organism that causes dental caries is a known phosphate-solubilising organism. This was, therefore, used as a positive control in the evaluation of the S. salivarius. Incubation was done for 14 days since maximum solubilisation would have occurred during this period (Goteti et al., 2014). After incubation, it was observed that $S$. mutans had a halo indicative of phosphate solubilisation whilst $S$. salivarius did not. Streptococcus salivarius was at this point considered a good candidate for the probiotic ODF.

Streptococcus salivarius strains are among the early colonisers of the oral cavity and are usually present in high numbers throughout the lifetime of the healthy host, with various benefits at any given age (Wescombe et al., 2012, Hale et al., 2012, Burton et al., 2005, Haukioja, 2010, Devine and Marsh, 2009). Xylitol has been used as a sweetener in chewing gums to prevent plaque formation. It has also been proven beneficial in preventing biofilm formation (Soderling, 2009, Badet et al., 2008).

The ODF was composed of two agents suggested to provide oral health benefits. Xylitol, as noted earlier, showed inhibition to the activity of $S$. mutans with little effect on $S$. salivarius. Hence, using an effective medium concentration of $0.5 \%$ xylitol (ink-jetted) with $S$. salivarius, it was expected that a complementary antibacterial activity would be obtained against $S$. mutans. The signals obtained indicated reduced metabolic activity in the ampoule. Due to the similarities between individual signals for $S$. mutans and $S$. salivarius, it was difficult to compare the nature of the peak obtained after co-incubation to that of the pure 
cultures. This highlighted a drawback with microbial calorimetry, especially when the species under investigation are closely related.

Plate counting data were, therefore, used to ascertain nature of reaction occurring in the coincubation tests. Mitis salivarius (MS) agar supports the growth of streptococci, however, when supplemented with $15 \%$ sucrose and 0.2 i.u of bacitracin per mL (MSBS) it selects for growth of S. mutans (Liljemark et al., 1976, Staat, 1976, Kurasz et al., 1986). Mitis salivarius and MSBS were, therefore, used for differentiation. Pure cultures of both species were streaked on MS and MSBS agar as references for comparison. S. salivarius on MS agar showed large, pale-blue, mucoid colonies that were glistening in appearance. S. mutans on MS agar showed raised, convex, undulate, opaque, pale-blue colonies that were granular in appearance (Hamada et al., 1979, Chapman, 1944). When pure cultures of both species were streaked on MSBS, no growth was observed for S. salivarius, however, characteristic colonies typical of $S$. mutans were obtained (images not shown).

With these references, enumeration of $S$. mutans post-calorimetry was conducted on MSBS. A decrease in numbers from 7.9 to 5.04-Log CFU/mL was obtained post-calorimetry for $S$. mutans co-incubated with ODF in comparison to $S$. mutans control. Although complete elimination of the $S$. mutans population was not obtained, this was promising as it represented a 2.86-Log reduction. Generally, when comparing the bactericidal activity of antimicrobials against bacteria, a 3-Log $(99.9 \%)$ reduction is considered to be significant; the reduction obtained here was, therefore, considered promising (Usacheva et al., 2014, Heffernan et al., 2013, Koh et al., 2013, Sun et al., 2014).

A streak-out post-calorimetry onto MS agar revealed some large, pale blue, glistening mucoid colonies characteristic of $S$. salivarius, however, enumeration was not possible due inability to select $S$. salivarius growth. This implied that $S$. salivarius was also present in the ampoule at the end of the experiment.

With probiotics reported to release materials with the ability to inhibit pathogenic species during metabolism, the objective of using CFS was to investigate any bacteriocin-like activity by the CFS from $S$. salivarius. Increasing the CFS volume was to serve as a means of increasing amounts of any bacteriocin-like substance that may be present then monitoring decrease in $S$. mutans numbers and metabolism with time. Cell-free supernatant from $S$. 
salivarius have been demonstrated to inhibit $S$. mutans activity and to play a role in preventing biofilm formation by S. mutans (Ogawa et al., 2011). In a similar approach, Fredua-Ageman et al., (2017) used varying amounts of freeze-dried CFS from L. acidophilus and Bifidobacterium lactis against Clostridium difficile. Amounts as high as 20-fold freezedried CFS from L. acidophilus and 5-fold freeze-dried CFS from B. lactis were needed to obtain complete inhibition. The quantity of CFS used in this work was much lower than the amounts used by Fredua-Ageman et al., which could account for the absence of complete inhibition of $S$. mutans by CFS from $S$. salivarius in this study. The reduction in $S$. mutans population with increasing amounts of CFS was, therefore, indicative of potential antimicrobial activity.

\section{Conclusion}

ODFs made of $S$. salivarius and xylitol were prepared and this exhibited some potential in the management of dental caries. A reduction in S. mutans numbers was observed after coincubating $S$. mutans together with ODFs made of S. salivarius and xylitol. The challenge in in-vitro evaluation evident here was due to these species belonging to the same genera limiting options available for differentiating. The approach, however, can be adapted in formulating probiotic ODFs using a variety of probiotic organisms to investigate of other conditions like periodontal disease and halitosis. 


\section{Declarations}

\section{Funding}

This research was funded by the Commonwealth Scholarship Commission

\section{Conflicts of interest}

The authors declare that they have no conflict of interest.

Ethics approval (include appropriate approvals or waivers)

This article does not contain any studies with animals or human participants.

\section{Authors' contributions}

Cornelius Dodoo: Conceptualization, methodology, investigation, visualization, data curation, formal analysis, writing - original draft

Paul Stapleton: Data curation, formal analysis, writing — review and editing

Abdul Basit: Data curation, formal analysis, writing - review and editing

Simon Gaisford: Conceptualization, methodology, investigation, visualization, data curation, formal analysis, writing — review and editing 


\section{References}

ABOU NEEL, E. A., ALJABO, A., STRANGE, A., IBRAHIM, S., COATHUP, M., YOUNG, A. M., BOZEC, L. \& MUDERA, V. 2016. Demineralizationremineralization dynamics in teeth and bone. International Journal of Nanomedicine, 11, 4743-4763.

ALOMARI, M., VUDDANDA, P. R., TRENFIELD, S. J., DODOO, C. C., VELAGA, S., BASIT, A. W. \& GAISFORD, S. 2018. Printing T3 and T4 oral drug combinations as a novel strategy for hypothyroidism. International Journal of Pharmaceutics, 549, 363-369.

ALPER, J. 2004. Biology and the Inkjets. Science, 305, 1895.

BADET, C., FURIGA, A. \& THÉBAUD, N. 2008. Effect of xylitol on an in vitro model of oral biofilm. Oral Health \& Preventive Dentistry, 6, 337-341.

BIZZINI, B., PIZZO, G., SCAPAGNINI, G., NUZZO, D. \& VASTO, S. 2012. Probiotics and oral health. Current Pharmaceutical Design, 18, 5522-5531.

BOWEN, D. M. 2012. Probiotics and oral health. The Journal of Dental Hygiene, 87, 5-9.

BRAISSANT, O., BONKAT, G., WIRZ, D. \& BACHMANN, A. 2013. Microbial growth and isothermal microcalorimetry: Growth models and their application to microcalorimetric data. Thermochimica Acta, 555, 64-71.

BRAISSANT, O., WIRZ, D., GOPFERT, B. \& DANIELS, A. U. 2010. Use of isothermal microcalorimetry to monitor microbial activities. FEMS Microbiol Lett, 303, 1-8.

BUANZ, A. B., BELAUNDE, C. C., SOUTARI, N., TULEU, C., GUL, M. O. \& GAISFORD, S. 2015. Ink-jet printing versus solvent casting to prepare oral films: Effect on mechanical properties and physical stability. Int J Pharm, 494, 611-8.

BURTON, J. P., CHILCOTT, C. N. \& TAGG, J. R. 2005. The rationale and potential for the reduction of oral malodour using Streptococcus salivarius probiotics. Oral Diseases, $11,29-31$.

CAGETTI, M. G., MASTROBERARDINO, S., MILIA, E., COCCO, F., LINGSTROM, P. \& CAMPUS, G. 2013. The use of probiotic strains in caries prevention: a systematic review. Nutrients, 5, 2530-50.

CAGLAR, E., KARGUL, B. \& TANBOGA, I. 2005. Bacteriotherapy and probiotics' role on oral health. Oral Diseases, 11, 131-137.

CAGLAR, E., TOPCUOGLU, N., CILDIR, S. K., SANDALLI, N. \& KULEKCI, G. 2009. Oral colonization by Lactobacillus reuteri ATCC 55730 after exposure to probiotics. Int J Paediatr Dent, 19, 377-81.

CHAPMAN, G. H. 1944. The isolation of streptococci from mixed cultures. J. Bacteriol., 48, 113.

CHUGH, P., DUTT, R., SHARMA, A., BHAGAT, N. \& DHAR, M. S. 2020. A critical appraisal of the effects of probiotics on oral health. Journal of Functional Foods, 70.

DEVINE, D. A. \& MARSH, P. D. 2009. Prospects for the development of probiotics and prebiotics for oral applications. J Oral Microbiol, 1.

DHAWAN, R. \& DHAWAN, S. 2013. Role of probiotics on oral health: A randomized, double-blind, placebo-controlled study. Journal of Interdisciplinary Dentistry, 3, 7178.

DODOO, C. C., ALOMARI, M., BASIT, A. W., STAPLETON, P. \& GAISFORD, S. 2019a. A thermal ink-jet printing approach for evaluating susceptibility of bacteria to antibiotics. J Microbiol Methods, 164, 105660.

DODOO, C. C., STAPLETON, P., BASIT, A. W. \& GAISFORD, S. 2019b. Use of a waterbased probiotic to treat common gut pathogens. Int J Pharm, 556, 136-141. 
DOMMISCH, H., KUZMANOVA, D., JÖNSSON, D., GRANT, M. \& CHAPPLE, I. 2018. Effect of micronutrient malnutrition on periodontal disease and periodontal therapy. Periodontology 2000, 78, 129-153.

FREDUA-AGYEMAN, M., STAPLETON, P., BASIT, A. W., BEEZER, A. E. \& GAISFORD, S. 2017. In vitro inhibition of Clostridium difficile by commercial probiotics: A microcalorimetric study. Int J Pharm, 517, 96-103.

GAURILCIKAITE, E., RENTON, T. \& GRANT, A. D. 2017. The paradox of painless periodontal disease. Oral Dis, 23, 451-463.

GOTETI, P. K., DESAI, S., EMMANUEL, L. D. A., TADURI, M. \& SULTANA, U. 2014. Phospahte solubilization potential of fluorescent Pseudomonas spp. isolated from diverse agro-ecosystems of India. International Journal of Soil Science, 9, 101- 110.

HALE, J. D. F., TAGG , J. R. \& WESCOMBE, P. A. 2012. BLIS-producing probiotics targeting the oral cavity. Microbiology Australia, 103 - 105.

HAMADA, S., MASUDA, N. \& SHIMAMOTO, T. 1979. Some biological properties of Streptococcus mutans isolated from human mouths, with reference to the correlation with serotypes. Archives of Oral Biology, 24, 627-631.

HARA, A. T. \& ZERO, D. T. 2010. The caries environment: saliva, pellicle, diet, and hard tissue ultrastructure. Dent Clin North Am, 54, 455-67.

HAUKIOJA, A. 2010. Probiotics and oral health. European Journal of Dentistry, 4, 348-355.

HEFFERNAN, R., SEMIÃO, A. J. C., DESMOND, P., CAO, H., SAFARI, A., HABIMANA, O. \& CASEY, E. 2013. Disinfection of a polyamide nanofiltration membrane using ethanol. Journal of Membrane Science, 448, 170-179.

HEINEMANN, R. J. B., CARVALHO, R. A. \& AVARO-TRINDADE, C. S. 2013. Orally disintegrating film (ODF) for delivery of probiotics in the oral cavity - Development of a novel product for oral health. Innovative Food Science and Emerging Technologies, 19, 227-232.

HUJOEL, P. P., HUJOEL, M. L. A. \& KOTSAKIS, G. A. 2018. Personal oral hygiene and dental caries: A systematic review of randomised controlled trials. Gerodontology, 35, 282-289.

KABANOVA, N., KAZARJAN, A., STULOVA, I. \& VILU, R. 2009. Microcalorimetric study of growth of Lactococcus lactis IL1403 at different glucose concentrations in broth. Thermochimica Acta, 496, 87-92.

KOH, J. J., QIU, S., ZOU, H., LAKSHMINARAYANAN, R., LI, J., ZHOU, X., TANG, C., SARASWATHI, P., VERMA, C., TAN, D. T., TAN, A. L., LIU, S. \& BEUERMAN, R. W. 2013. Rapid bactericidal action of alpha-mangostin against MRSA as an outcome of membrane targeting. Biochim Biophys Acta, 1828, 834-44.

KRAMPE, R., VISSER, J. C., FRIJLINK, H. W., BREITKREUTZ, J., WOERDENBAG, H. J. \& PREIS, M. 2016. Oromucosal film preparations: points to consider for patient centricity and manufacturing processes. Expert Opin Drug Deliv, 13, 493-506.

KUMAR MEENA, R., KUMAR SINGH, R., PAL SINGH, N., KUMARI MEENA, S. \& SINGH MEENA, V. 2015. Isolation of low temperature surviving plant growth promoting rhizobacteria (PGPR) from pea (Pisum sativum L.) and documentation of their plant growth promoting traits. Biocatalysis and Agricultural Biotechnology, 4, 806-811.

KURASZ, A. B., TANZER, J. M., BAZER, L. \& SAVOLDI, E. 1986. In vitro studies of growth and competition between S. salivarius TOVE-R and mutans streptococci. $J$ Dent Res, 65, 1149-53.

LADEWIG, N. M., CAMARGO, L. B., TEDESCO, T. K., FLORIANO, I., GIMENEZ, T., IMPARATO, J. C. P., MENDES, F. M., BRAGA, M. M. \& RAGGIO, D. P. 2018. 
Management of dental caries among children: a look at the cost-effectiveness. Expert Rev Pharmacoecon Outcomes Res, 18, 127-134.

LEMMO, A. V., ROSE, D. J. \& TISONE, T. C. 1998. Inkjet dispensing technology: applications in drug discovery. Current Opinion in Biotechnology, 9, 615-617.

LILJEMARK, W. F., OKRENT, D. H. \& BLOOMQUIST, C. G. 1976. Differential recovery of Streptococcus mutans from various Mitis-Salivarius agar preparations. Journal of Clinical Microbiology, 108-109.

LIN, T.-H., LIN, C.-H. \& PAN, T.-M. 2017. The implication of probiotics in the prevention of dental caries. Applied Microbiology and Biotechnology, 102, 577-586.

MANIRUZZAMAN, M., BOATENG, J. S., SNOWDEN, M. J. \& DOUROUMIS, D. 2012. A review of hot-melt extrusion: process technology to pharmaceutical products. ISRN Pharm, 2012, 436763.

MARSH, P. D. 2003. Are dental diseases examples of ecological catastrophes? Microbiology, 149, 279-94.

MEURMAN, J. H. 2005. Probiotics: do they have a role in oral medicine and dentistry? European Journal of Oral Sciences, 113, 188-196.

OGAWA, A., FURUKAWA, S., FUJITA, S., MITOBE, J., KAWARAI, T., NARISAWA, N., SEKIZUKA, T., KURODA, M., OCHIAI, K., OGIHARA, H., KOSONO, S., YONEDA, S., WATANABE, H., MORINAGA, Y., UEMATSU, H. \& SENPUKU, H. 2011. Inhibition of Streptococcus mutans biofilm formation by Streptococcus salivarius FruA. Appl Environ Microbiol, 77, 1572-80.

OHSHIMA, T., KOJIMA, Y., SENEVIRATNE, C. J. \& MAEDA, N. 2016. Therapeutic Application of Synbiotics, a Fusion of Probiotics and Prebiotics, and Biogenics as a New Concept for Oral Candida Infections: A Mini Review. Front Microbiol, 7, 10.

PREIS, M., WOERTZ, C., KLEINEBUDDE, P. \& BREITKREUTZ, J. 2013. Oromucosal film preparations: classification and characterization methods. Expert Opin Drug Deliv, 10, 1303-17.

SAID, J., DODOO, C. C., WALKER, M., PARSONS, D., STAPLETON, P., BEEZER, A. E. \& GAISFORD, S. 2014. An in vitro test of the efficacy of silver-containing wound dressings against Staphylococcus aureus and Pseudomonas aeruginosa in simulated wound fluid. International Journal of Pharmaceutics, 462, 123-128.

SCARPA, M., STEGEMANN, S., HSIAO, W.-K., PICHLER, H., GAISFORD, S., BRESCIANI, M., PAUDEL, A. \& ORLU, M. 2017. Orodispersible films: Towards drug delivery in special populations. International Journal of Pharmaceutics, 523, 327-335.

SODERLING, E. M. 2009. Xylitol, mutans streptococci, and dental plaque. Adv Dent Res, 21, 74-8.

STAAT, R. H. 1976. Inhibition of Streptococcus mutans strains by different mitis-salivarius agar preparations. Journal of Clinical Microbiology, 3, 378 - 380.

SUN, Y., WANG, L., LI, J., ZHAO, C., ZHAO, J., LIU, M., WANG, S., LU, C., SHANG, G., JIA, Y. \& WEN, A. 2014. Synergistic efficacy of meropenem and rifampicin in a murine model of sepsis caused by multidrug-resistant Acinetobacter baumannii. Eur J Pharmacol, 729, 116-22.

TAGG, J. R. \& DIERKSEN, K. P. 2003. Bacterial replacement therapy: adapting 'germ warfare' to infection prevention. Trends in Biotechnology, 21, 217-223.

TESTER, R. F. \& AL-GHAZZEWI, F. H. 2018. Role of prebiotics and probiotics in oral health. Nutrition \& Food Science, 48, 16-29.

USACHEVA, E. A., GRAYES, A., SCHORA, D. \& PETERSON, L. R. 2014. Investigation of tigecycline bactericidal activity: Optimisation of laboratory testing. $J$ Glob Antimicrob Resist, 2, 269-275. 
VUDDANDA, P. R., ALOMARI, M., DODOO, C. C., TRENFIELD, S. J., VELAGA, S., BASIT, A. W. \& GAISFORD, S. 2018. Personalisation of warfarin therapy using thermal ink-jet printing. European Journal of Pharmaceutical Sciences, 117, 80-87.

WESCOMBE, P. A., HALE, J. D. F., HENG, N. C. K. \& TAGG, J. R. 2012. Developing oral probiotics from Streptococcus salivarius. Future Microbiology, 7, 1355-1371.

WILSON, W. C., JR. \& BOLAND, T. 2003. Cell and organ printing 1: protein and cell printers. Anat Rec A Discov Mol Cell Evol Biol, 272, 491-6.

YAO, S. G. \& FINE, J. B. 2014. Probiotics for bacterial disease treatment in the oral environment. COMPENDIUM, 35, 658 - 663. 
Figures
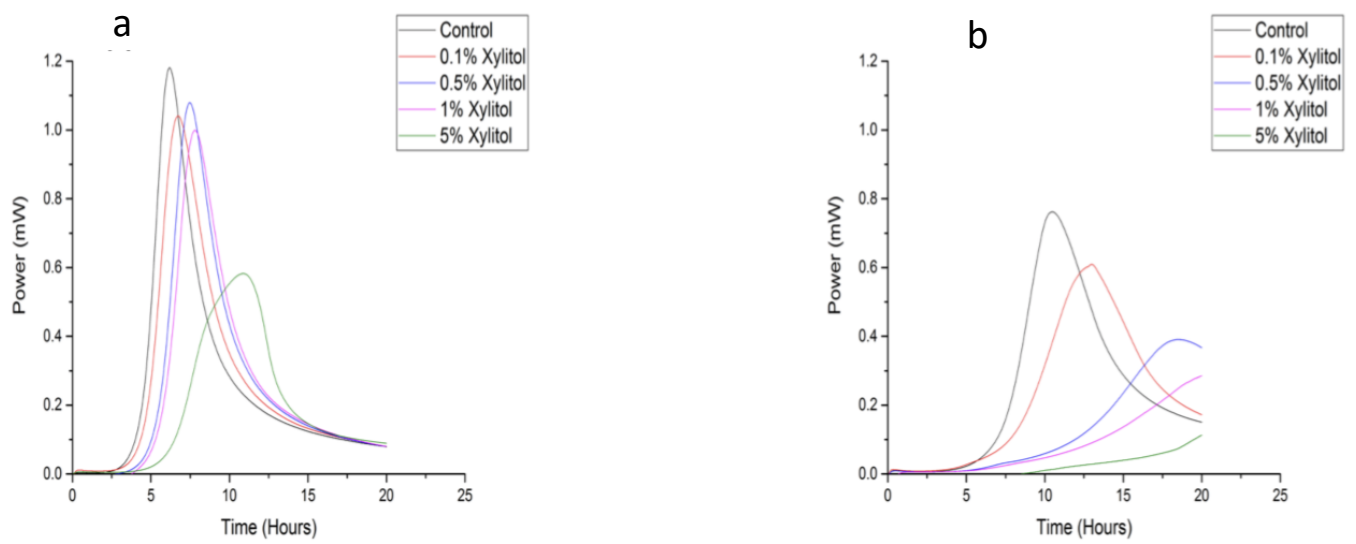

Figure 8 Effect of varying xylitol concentrations on S. salivarius growth (a) and S. mutans growth (b)

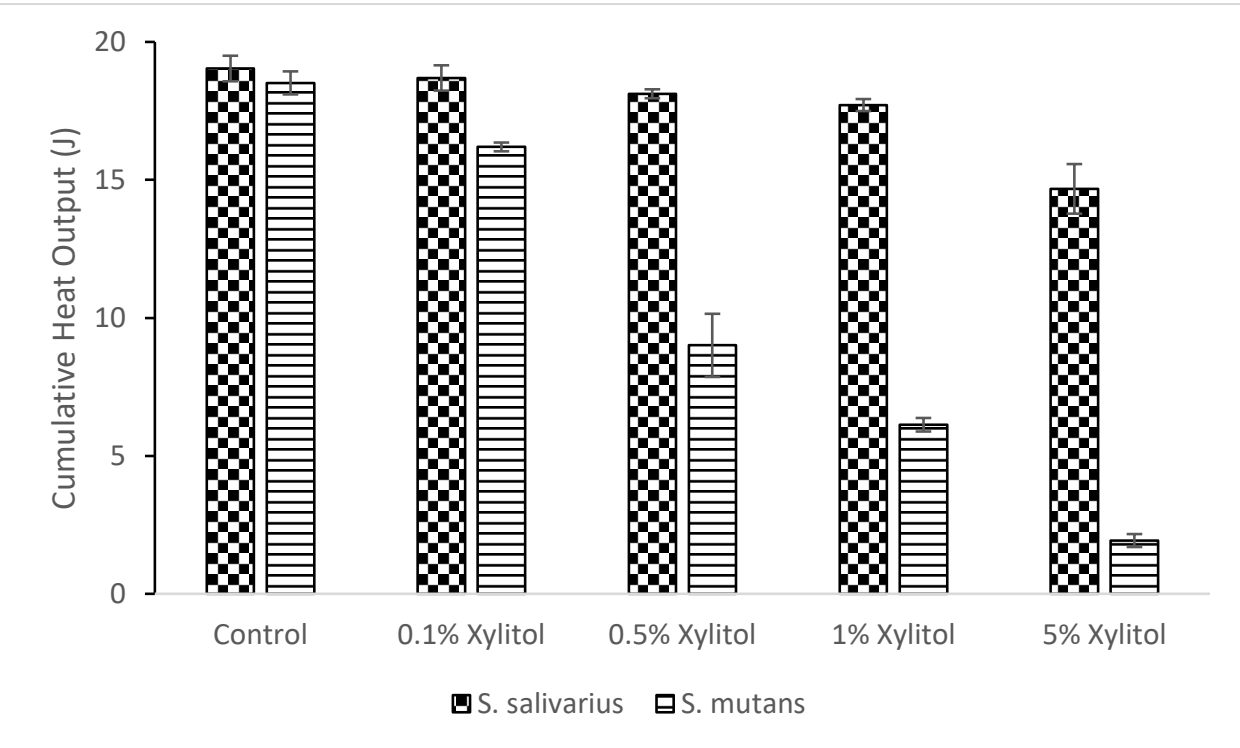

Figure 9 Cumulative heat output representative of total AUC for S. salivarius and S. mutans under varying xylitol concentrations 


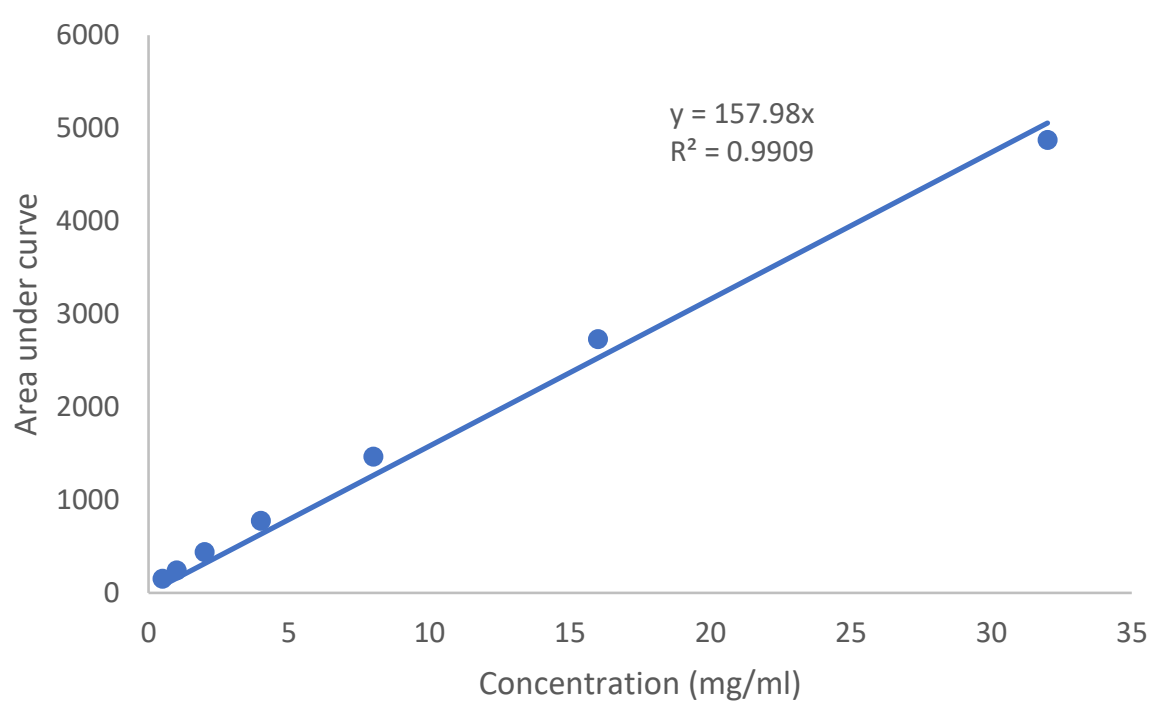

Figure 10 Calibration curve for xylitol in the range 0.5 to $32 \mathrm{mg} / \mathrm{ml}$

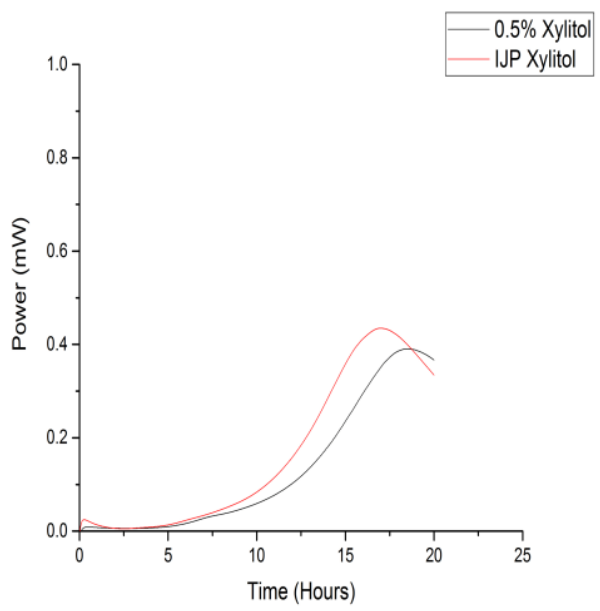

Figure 11 A Power-Time plot comparing metabolism of S. mutans in the presence of $0.5 \%$ xylitol and inkjetted equivalent 
a

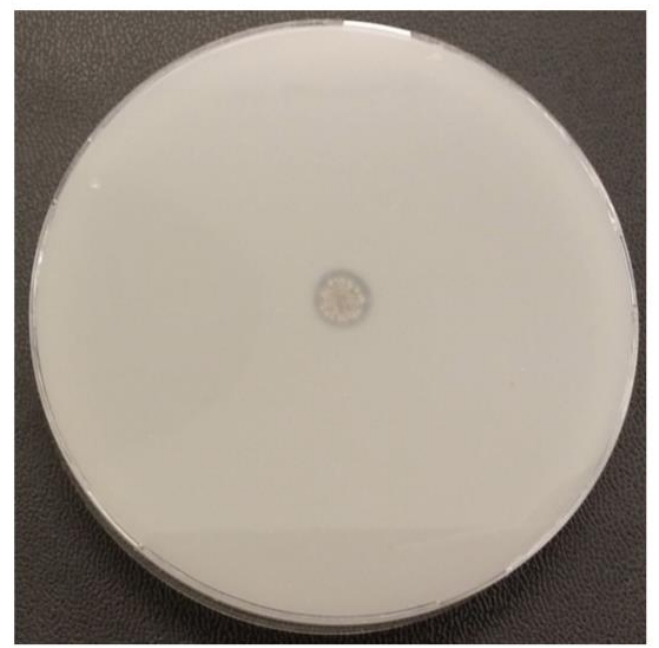

b

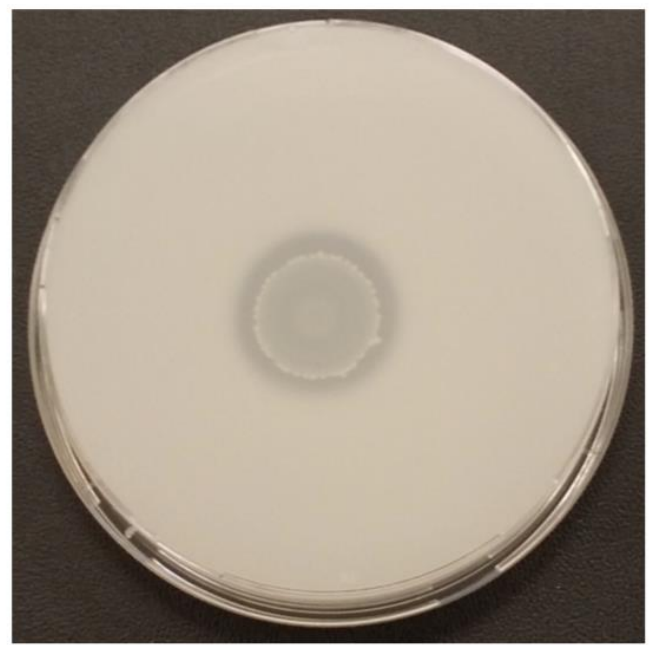

Figure 12 Images after incubating S. salivarius (a) and S. mutans (b) on pikovskaya agar with S. mutans having a halo with a diameter of $16 \mathrm{~mm}$ around the site of the inoculum
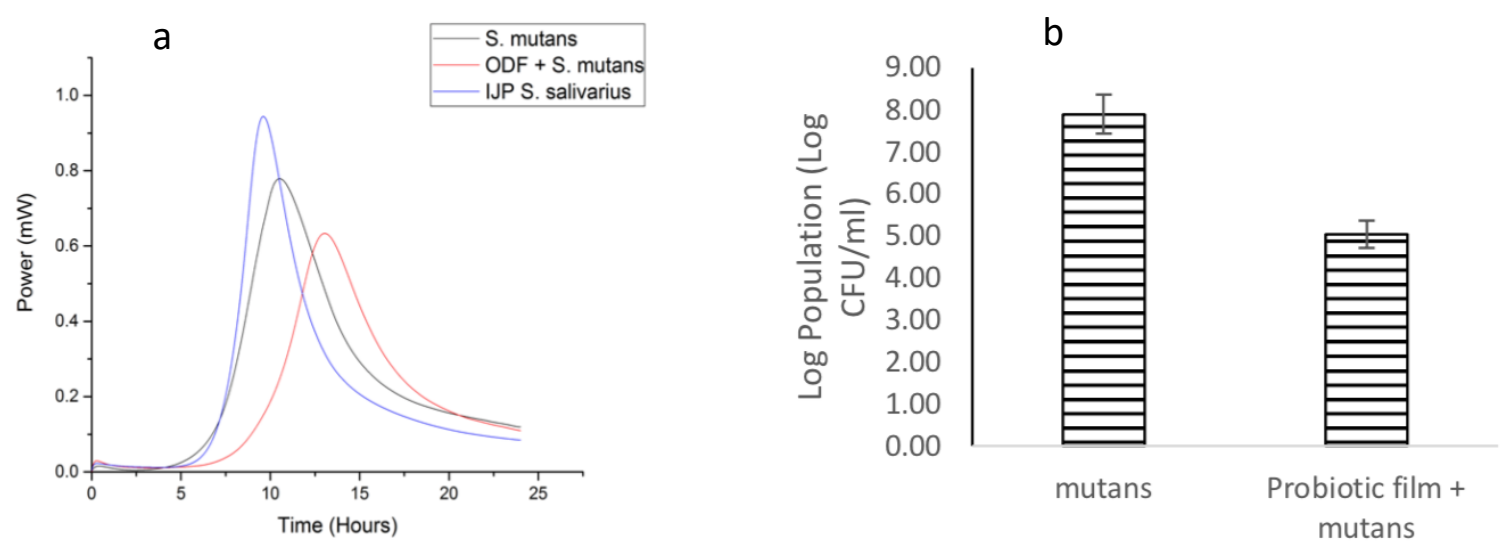

Figure 13 a) A Power-Time plot of S. mutans (control), ink-jetted (IJP) S. salivarius, and co-incubation of probiotic oro-dispersible film (ODF) and S. mutans

b) Colony plate counts of S. mutans control and S. mutans after co-incubating with probiotic ODF 

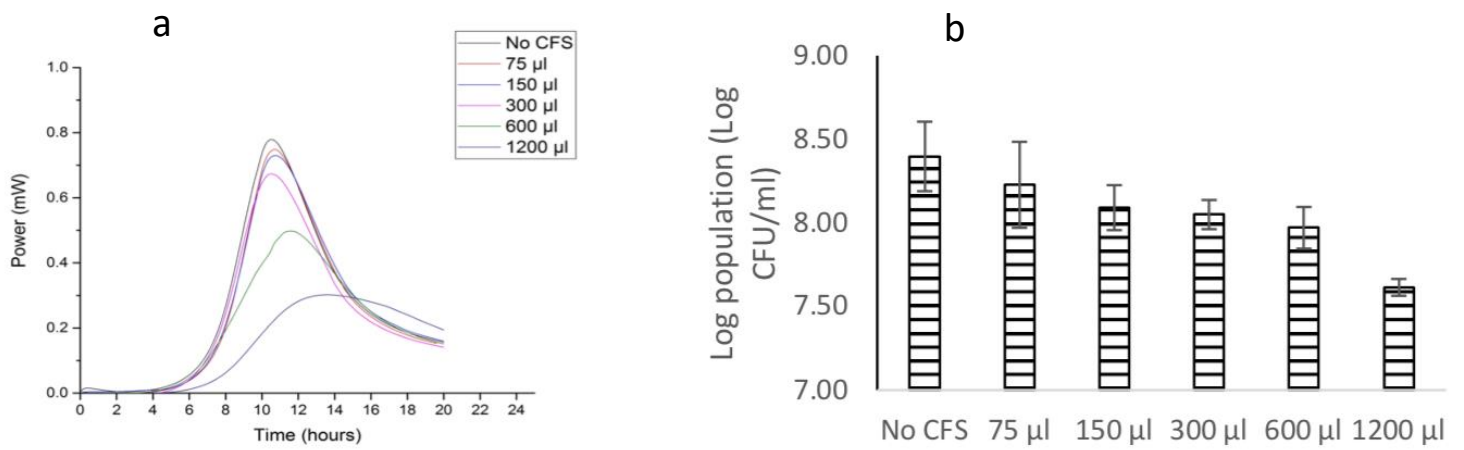

Figure 14 a) A Power-Time plot of $S$. mutans in varying amounts of $S$. salivarius cell-free supernatant b) Enumeration of $S$. mutans population at the highest signal intensity 
Table 3 Pikovskaya medium composition in $1 \mathrm{~L}$

\begin{tabular}{|l|l|}
\hline Ingredient & Quantity $(\mathbf{g})$ \\
\hline Glucose & 10 \\
\hline Tricalcium Phosphate & 5 \\
\hline Ammonium sulphate & 0.5 \\
\hline Yeast extract & 0.5 \\
\hline Sodium chloride & 0.2 \\
\hline Potassium chloride & 0.2 \\
\hline Magnesium sulphate heptahydrate & 0.1 \\
\hline Manganese sulphate monohydrate & 0.002 \\
\hline Ferrous sulphate heptahydrate & 0.002 \\
\hline Agar & 20 \\
\hline
\end{tabular}

Table 4 Varying template dimensions used for ink-jetting xylitol and corresponding area under curve (AUC) $(n=3)$

\begin{tabular}{|l|l|}
\hline Template Dimension $(\mathbf{c m} \times \mathbf{~ c m})$ & AUC \\
\hline $\mathbf{1} \times 1$ & $149.10 \pm 19.98$ \\
\hline $\mathbf{1} \times \mathbf{2}$ & $277.00 \pm 29.09$ \\
\hline $\mathbf{1} \times \mathbf{4}$ & $434.87 \pm 20.46$ \\
\hline $\mathbf{1} \times \mathbf{8}$ & $802.13 \pm 2.42$ \\
\hline $\mathbf{1} \times \mathbf{1 6}$ & $1540.40 \pm 14.68$ \\
\hline $\mathbf{2} \times \mathbf{1}$ & $275.20 \pm 7.88$ \\
\hline $\mathbf{2} \times \mathbf{2}$ & $495.00 \pm 12.13$ \\
\hline $\mathbf{2} \times \mathbf{4}$ & $820.83 \pm 17.29$ \\
\hline $\mathbf{2} \times \mathbf{8}$ & $1574.60 \pm 41.58$ \\
\hline $\mathbf{2} \times \mathbf{1 6}$ & $2830.20 \pm 16.46$ \\
\hline
\end{tabular}


